NBER WORKING PAPER SERIES

\title{
MEASURING THE BENEFITS OF PRODUCT VARIETY WITH AN ACCURATE VARIETY SET
}

Bruce A. Blonigen

Anson Soderbery

Working Paper 14956

http://www.nber.org/papers/w14956

\author{
NATIONAL BUREAU OF ECONOMIC RESEARCH \\ 1050 Massachusetts Avenue \\ Cambridge, MA 02138
}

May 2009

This paper has benefited from the comments of Robert Feenstra, Ankur Patel, Katheryn Russ, Deborah Swenson, and workshop participants at the University of California-Davis. Any remaining errors or omissions are our own. The views expressed herein are those of the author(s) and do not necessarily reflect the views of the National Bureau of Economic Research.

NBER working papers are circulated for discussion and comment purposes. They have not been peerreviewed or been subject to the review by the NBER Board of Directors that accompanies official NBER publications.

(C) 2009 by Bruce A. Blonigen and Anson Soderbery. All rights reserved. Short sections of text, not to exceed two paragraphs, may be quoted without explicit permission provided that full credit, including (C) notice, is given to the source. 
Measuring the Benefits of Product Variety with an Accurate Variety Set

Bruce A. Blonigen and Anson Soderbery

NBER Working Paper No. 14956

May 2009

JEL No. F12,F23,L16

\begin{abstract}
$\underline{\text { ABSTRACT }}$
Recent studies have used import data to assess the impact of foreign varieties on prices and welfare for a home country. The reliance on import data has a number of limitations. First, these papers rely on goods categories defined by the Harmonized System. Second, they define varieties using the Armington assumption that all imports coming from a particular country are one unique variety. Third, they ignore variety changes that may occur through foreign affiliate activity. In this paper, we revisit this literature by employing a detailed market-based data set on the U.S. automobile market that allows us to define goods varieties at a more precise level, as well as discern location of production and ownership of varieties. We show that estimated variety changes and their impacts on U.S. prices and welfare differ markedly for automobiles depending on whether one uses the standard import data or our more detailed market-based data. The import data and Armington assumption hide significant net variety change leading to a downward bias in the effects of net variety change, with implied welfare benefits only half what we find with our market-based data. We also show that the welfare gains from all foreign-owned varieties (both imported and from foreign affiliates) are well over 50\% larger than that stemming from imported varieties alone.
\end{abstract}

Bruce A. Blonigen

Department of Economics

1285 University of Oregon

Eugene, OR 97403-1285

and NBER

bruceb@uoregon.edu

Anson Soderbery

Department of Economics

University of California - Davis

Davis, CA 95616

asoderbe@gmail.com 


\section{Introduction}

The seminal work of Krugman (1979) highlights that the benefits of trade may stem not only from lower prices, but also greater product variety. This has generated considerable subsequent literature focused on the role of product variety in international trade and its welfare effects. A crucial innovation in this literature is Feenstra (1994) which develops a method for adjusting price indexes to account (discount) for new (disappearing) varieties. Using this method one can calculate the impact of new imported product varieties on not only economywide prices, but also aggregate welfare. Implementing Feenstra (1994)'s methodology and using highly-detailed product-level U.S. import data, Broda and Weinstein (2006) estimate that the substantial rise in new imported varieties over the 1972-2001 period suggests a 1.2 percentage point lower effective aggregate import price per year than that estimated by a conventional import price index. This translates into a cumulative U.S. welfare gain from new imported varieties that is equivalent to roughly $2.6 \%$ of U.S. GDP.

While understanding the origins and impact of new varieties on international trade patterns and outcomes has been a recent focus in the literature, empirical analysis of these issues is handicapped by the lack of data on varieties. Empirical studies of the role of product varieties in international trade have exclusively relied on an Armington-type assumption where each country import source for a given product code represents one unique variety. ${ }^{1}$

In this paper we explore how severe the measurement bias may be from the previous product variety assumptions by revisiting the effect of new foreign varieties on prices and welfare for goods where we can very accurately determine varieties: automobiles. Data on automobiles are very carefully documented in well-known publications by make and models, which we use to define unique varieties. We call these data our market data since they rely on market-based categories of automobile varieties. There are obvious examples of how different variety classifications will be in the market data than the standard import data used in previous studies. For instance, whereas the standard import data would classify all makes and models from Japan as one variety for a given automobile good (say, compact cars), our market data would show numerous varieties, including Honda Civic, Toyota Corolla, Nissan

\footnotetext{
${ }^{1}$ Both Feenstra (1994) and Broda and Weinstein (2006) undertake a brief discussion of pitfalls of this restrictive documentation of varieties, but ultimately must settle on measuring varieties by import source due to data limitations.
} 
Sentra, Mitsubishi Lancer, etc. A related issue we will show is that the Harmonized System (HS) goods codes do not map very well into accepted market-based definitions of automobile goods. For example, compact cars are classified under numerous HS 10-digit codes and often lumped with sports cars.

Standard import data may provide biased estimates of price changes and welfare for other reasons beyond this precision issue with measuring goods and varieties. First, some varieties that are counted as "new" imported varieties may simply be production of existing varieties that are offshored to foreign production locations and then imported back to the home economy. Such varieties should likely not be considered new. ${ }^{2}$ Second, foreign producers may introduce new varieties to an economy through new foreign affiliate production that is obviously not included in import data. Our data provide locations of production for each variety, as well as ownership of production. Thus, we can accurately measure new imported varieties, as well as estimate the effect of new varieties not only from imports, but also from foreign-affiliate production.

Our results first show that the market-based data uncover product variety churning (entering and exiting of varieties) that is orders of magnitude larger market-based data than what is represented in the standard import data. The Armington assumption "hides" substantial variety change. Applying the methods of Feenstra (1994) and Broda and Weinstein (2006) to these respective datasets, we find that the estimated impact of new net variety change on price indexes and, hence, consumer welfare is roughly double in magnitude when calculated using our market data versus the import data. Our market data allow us to also examine a number of other issues that one cannot with the import data. First, we show that the introduction of new varieties and their impact on effective consumer prices has been greater from import varieties than domestic varieties over our sample. We also have data on both location and ownership of varieties and therefore can examine the total impact of variety change from foreign sources (both imports and foreign affiliate activity in the U.S.) We show that the additional introduction of new varieties by foreign affiliates adds gains that are around $65 \%$ larger than those calculated from only import sources. In summary,

\footnotetext{
${ }^{2}$ For example, a Honda Civic produced at time $t$ in Japan and then at $t+1$ in Japan and Mexico will not be considered a gain of a new variety using market level data, but very well may be considered a variety gain using import data.
} 
misclassification of goods and varieties by import data, along with the implicit omission of variety change from foreign affiliate activity, leads to a very large underestimate of net new variety impact for our sample of the U.S. automobile market. Finally, we show that our results are virtually identical whether we make calculations using three-year intervals or annual changes, suggesting that new varieties quickly reach their equilibrium market share when first introduced.

While our exercise applies specifically to automobiles and cannot be easily applied to other products in the absence of similarly detailed market data, we note that automobiles are a significant share of U.S. imports and foreign-affiliate sales in the U.S. Using data from the Center of International Data, we calculate the fraction of automobile imports by value to be $9.4 \%$ (by value) of all U.S. imported manufactured products, and $14.7 \%$ of all differentiated products, ${ }^{3}$ during the period 1990-2005. In addition, BEA statistics show affiliate sales of motor vehicles to be $11.6 \%$ (by value) of all manufacturing affiliate sales by firms in the U.S. as of 2002. Thus, the automobile sector comprises a significant share of all differentiated products delivered to the U.S. from "foreign" sources.

The paper proceeds as follows. The next section describes the detailed market-based data we have collected for automobiles, comparing it to the import data with HS10 product classifications for autos that have been used by prior studies. Section 3 briefly reviews the standard methodology developed by Feenstra (1994) and Broda and Weinstein (2006) to account for variety change on price indexes before turning to section 4 which implements this methodology for our two automobile data sets and directly compares the magnitude of net variety change and welfare. Section 4 also examines further issues, including the effect of foreign affiliate activity on gains from variety change and the robustness of results to varying the time interval used to calculate net variety change. Section 5 concludes.

\section{Data}

The contribution of our paper stems directly from the use of a more accurate data set of automobile varieties. A number of prior industrial organization studies have used automobile data to empirically study trade policy effects, price discrimination practices, and even

\footnotetext{
${ }^{3}$ We use the classification proposed by Rauch (1999) to define differentiated products.
} 
technological innovation in this industry using detailed data on specific makes and models of automobiles. ${ }^{4}$ Such data for the U.S. market can be gathered from Ward's Automotive Yearbook and Automotive News Market Data Book, and include information on model characteristics (height, width, horsepower, etc.), as well as units sold and listed retail prices. For our purposes, we gathered data from these sources on units sold, listed retail prices, manufacturer, and locations of production for all passenger vehicles sold in the United States from 1990 through 2005. ${ }^{5}$ With these data, we define "goods" as various categories of automobiles that are commonly used by industry organizations to classify types of vehicles primarily by size; namely "subcompact", "compact", "midsize", etc. We then define "varieties" of these goods as specific makes and models of automobiles. Dodge Neon, Ford Focus, Mazda 3, Toyota Corolla, and Volkswagen Jetta are examples of varieties of "compact" automobiles sold during our sample. We will call this data sample our "market data." Table 1 provides a list of the goods in our market data and counts of varieties for each good.

We contrast this with the type of data used by prior studies to evaluate the effects of new imported varieties on prices and welfare. These studies rely on what we call "import data," which for the U.S. are import data collected by U.S. Customs by 10-digit Harmonized System (HS10) codes. We collect these data from the Center for International Studies at $\mathrm{UC}^{-D a v i s}{ }^{6}$, which provide units of automobiles sold and unit-value prices by country and HS10 combination. Using import data, "goods" are defined as individual HS10 categories and "varieties" are, by an Armington-style assumption, each unique country-level import source. For example, for a given 10-digit HS code, imports from Japan are one unique variety, imports from Germany are another unique variety, etc. Table 2 provides a list of the goods for our import data on passenger automobiles, as well as counts of varieties for each good.

There are a number of important advantages of the market data over the import data. The primary issue is the definition of varieties and the potential for the import data to hide variety change. We know that for many import sources of a good, especially ones that

\footnotetext{
${ }^{4}$ Representative studies in this literature include Goldberg (1995), Berry, Levinsohn and Pakes (1995), Verboven (1996), Berry, Levinsohn and Pakes (1999), Petrin (2002), and Goldberg and Verboven (2005)

${ }^{5}$ Following previous studies using automobile data, our retail prices are for base packages of a model.

${ }^{6}$ Data can be found at, http://cid.econ.ucdavis.edu/
} 
account for significant market share, there are multiple goods that consumers would see as different varieties. It is clear to see this in our market data. For example, there are many Japanese automobile producers that ship their unique model of automobile and which all fall under the same HS10, yet the import data treats these all as one unique variety. This has the potential to hide significant changes in varieties over time as automobile firms discontinue or introduce new models.

Indeed, as shown in Table 3, there are significant differences in observed variety change for automobile goods between the two data sets. Columns 1 and 2 show average annual number of new and exiting varieties per good across the two data sets, while columns 3 and 4 show the average annual share of new and exiting varieties in total sales for a given year. The bottom row for each data set panel provides weighted averages across the goods categorized in each data set. As one can see, new annual varieties per good are 1.9 on average for the import data, while significantly higher at 2.5 for the market data set. The average number of exiting varieties is more similar across the data sets, which means that the market data reveal much greater net new variety -1.27 versus 0.26 . More importantly for measuring the importance of net new variety is the share of these new and exiting varieties in total annual sales. Here, the differences are much more stark. The average share of new varieties is an order of magnitude higher in the market data than the import data (5.9\% versus $0.4 \%$ ). The average share of new variety in the market data is $3.0 \%$, while only $0.1 \%$ for the import data. An important factor in these patterns is that the import data show a number of lowvolume imports from countries with no known automobile production. These are presumably transactions where a final consumer purchased a car in the foreign country and arranged to have it personally shipped, rather than manufacturer shipments. This inflates the amount of churning one sees in terms number of new varieties in the import data when just counting varieties, but then shows little churning in terms of the market share component of these "new" varieties.

A related advantage of our market data is the ability to determine the ownership of a variety so that we do not confound "domestic" and "foreign" varieties. The following are two stark examples to show how the import data can confound this distinction and lead to serious measurement biases of variety change from foreign sources. Suppose that all 
imports for a given good are coming from U.S.-owned firms who decided to outsource the production of existing varieties (formerly produced domestically) to various foreign countries. The import data would then suggest new variety introduction through imports when, in fact, U.S. consumers would not be enjoying any new varieties. ${ }^{7}$ The opposite example is where foreign firms introduce all new varieties through foreign affiliate production in the U.S., not through their imports. In this case, the import data show no new variety change, ${ }^{8}$ even though U.S. consumers are enjoying new foreign varieties through foreign-affiliate production and sales in the U.S. The general message is clear. Import data cannot identify outsourced production which creates a bias toward finding more import variety change than really exists. Import data also ignore foreign affiliate production which creates a bias toward finding less foreign variety change than really exists. How these two effects net out is obviously an empirical question.

Our market data can directly address this issue because we have automobile production data by location for each make and model, even when it is produced in more than one location. Thus, we can examine the price and welfare effects of variety changes from "foreignowned" manufacturers as a question distinct from variety changes from imports only. In doing so, we will also not confound outsourced production of existing varieties by U.S. manufacturers as new varieties to U.S. consumers. The automobile sector is an excellent example to investigate these issues as the value of foreign-affiliate production of automobiles in the U.S. rivals the value of imported automobiles, as mentioned in the introduction. In addition, U.S. manufacturers have significantly increased their outsourcing of automobile models, especially to North American Free Trade Area countries, over our sample period.

Beyond variety definitions, a likely final advantage of the market data over the import data is the classification of goods. While the HS10 classifications are fairly narrowly defined over various car sizes, this does not always correspond well with typical classifications made by automobile industry sources. Table 4 provides a basic concordance between goods in our

\footnotetext{
${ }^{7}$ This assumes that consumers either are not informed about production location or do not differentiate between automobile models that are identical except for production location. Anecdotally, to "buy American" implies purchasing either a General Motors, Ford, or Chrysler vehicle. However, these companies outsource a significant percentage of their production, including entire model lines, most frequently to Canada and Mexico.

${ }^{8}$ The data may even show losses of varieties if production of an entire good is transplanted.
} 
import data and goods in our market data. Virtually all the HS10 goods span multiple goods in the market data. For example, HS good 8703230046 may contain "compact" automobiles, as well as "sports" and "sport compact" automobiles. ${ }^{9}$ This is of concern for the estimation of elasticities of substitution since one would expect that such elasticities would be significantly different for "compact" automobiles versus "sport" automobiles. Lumping such dissimilar automobiles into the same good can then bias these elasticity estimates. There are many other such examples of dissimilar automobiles falling under the same HS10 classification in Table 4 .

There is one dimension in which the import data good categories may be preferred to those in our market data. The import data distinguish automobile goods by cylinders and cylinder volume. Ideally, our market data would have not only sales and prices by make and model, but also by various packages of models (or "trim" levels) offered. For example, in many models one can upgrade from a 4-cylinder version of a model to a 6-cylinder version. Our market data does not provide individual data on sales by these various packages for each variety. However, we believe that the elasticity of substitution differences across these dimensions (and resulting bias of pooling them as one variety) are likely less serious than the pooling across major automobile classifications, such as "compact" versus "sport" automobiles. ${ }^{10}$

\footnotetext{
${ }^{9}$ Establishing a concordance between the import data and market data is not always straightforward. We first use the U.S. Customs' definition of the good then compare the characteristics of the imported goods with the EPA's classification of vehicle classes, and concord goods with overlapping characteristics. Specialty vehicles, such as "sports" and "luxury" autos are the most difficult to concord. For the most part these vehicles do not follow stringent definitions, and we may conceivably observe their imports in seemingly unrelated groups.

${ }^{10} \mathrm{~A}$ related issue is measurement error in our price data if actual transaction prices differ from suggested retail prices that we use as our price variable in the market data. This is assuredly true in many cases, however we expect the differences to be small. We also have data on the prices of different trim levels for all models and have investigated using a simple average of these prices. The results differ insignificantly, and we find using prices of the baseline model most tractable as a simple average likely gives more weight to the expensive trim levels than is appropriate.
} 


\section{Methodology}

\subsection{Nested CES Model}

In this section, we briefly review the methodology developed by Feenstra (1994) and expanded upon by Broda and Weinstein (2006), to account for product variety change in price indexes which can then be translated into welfare changes for an economy.

Specify the upper level of the nested CES utility function as,

$$
U_{t}=\left(\sum_{X=D, M} X_{t}^{\frac{\kappa-1}{\kappa}}\right)^{\frac{\kappa}{\kappa-1}}, \quad \text { with } \quad \kappa>1
$$

where $\kappa$ represents the elasticity of substitution between $D_{t}$, the composite domestic good, and $M_{t}$ the composite imported good. We define the composite good in the second tier of the utility function as,

$$
X_{t}=\left(\sum_{g \in G} X_{g t}^{\frac{\gamma_{x}-1}{\gamma_{x}}}\right)^{\frac{\gamma_{x}}{\gamma_{x}-1}}, \quad \text { with } \gamma_{x}>1 \text { and } X=D, M
$$

The subutility derived from the consumption of the imported or domestic goods from the set of all goods $g \in G$ in time $t$ is denoted by $X_{g t}$. The elasticity of substitution across goods in the set of all imported goods is denoted by $\gamma_{M}$ when $X=M$. As in the recent works of Broda and Weinstein (2006) and Imbs and Mejean (2008), the second tier differentiates across HS10 goods. Alternatively, our market-based data defines goods by the categories listed in Table 1.

The focus of Feenstra (1994) is to characterize consumers' choices given they have chosen a product group. Thus, he limits his analysis to the third tier utility function given by,

$$
X_{g t}=\left(\sum_{v \in V} b_{g v t}^{\frac{1}{\sigma_{g}}} x_{g v t}^{\frac{\sigma_{g}-1}{\sigma_{g}}}\right)^{\frac{\sigma_{g}}{1-\sigma_{g}}}, \quad \text { with } \quad \sigma_{g}>1 \forall g \in G .
$$

Nonsymmetry in our third tier CES function comes from the taste parameter, $b_{g v t}$, which varies across goods and varieties. Consumption of a particular variety of a given good in a 
particular time period, $v \in V$, is $x_{g v t}$.

A valid concern one may raise from this representative consumer specification for automobiles is that individual consumers are likely not purchasing continuous quantities of each variant. Automobiles are an infrequently purchased durable good that lend themselves to the concept of discrete choice. In fact, the bulk of the industrial organization literature maintains discrete choice individual utility for consumers. ${ }^{11}$ However, Anderson, dePalma and Thisse (1992) demonstrate that an economy consisting of consumers who choose a variable amount of variety $v$ in time period $t$ obtaining indirect utility,

$$
u_{g v t}^{h}=\ln (y)-\alpha_{g} \ln \left(b_{g v t}^{\frac{1}{\alpha_{g}}} p_{g v t}\right)+\epsilon_{g v t}^{h}, \quad \text { where } \quad \alpha_{g}=\sigma_{g}-1>0
$$

such that their budget shares allocated to the selected variant is the same for all variants and prices, is theoretically equivalent to the preceding third tier of our CES representative consumer model. ${ }^{12}$ Thus, allowing for a nested discrete choice of similar form, we can reconcile these seemingly disjoint economies.

\subsection{Price Index}

The resulting unit cost requirement of Equation 3 is readily shown to be,

$$
\phi_{g t}^{X}\left(I_{g t}, \mathbf{b}_{g t}\right)=\left(\sum_{v \in I_{g t}} b_{g v t} p_{g v t}^{1-\sigma_{g}}\right)^{\frac{1}{1-\sigma_{g}}}
$$

Substituting in each preceding tier of the nested CES utility produces the overall price index,

$$
p_{t}=\left(\sum_{X=D, M}\left(\phi_{t}^{X}\right)^{1-\kappa}\right)^{\frac{1}{1-\kappa}}, \text { where } \phi_{t}^{X}=\left(\sum_{g \in G}\left(\phi_{g t}^{X}\left(I_{g t}, \mathbf{b}_{g t}\right)\right)^{1-\gamma}\right)^{\frac{1}{1-\gamma}}
$$

\footnotetext{
${ }^{11}$ There is a rich history of work dealing with the estimation of the underlying demand and supply structure in the automobile market. Goldberg (1995) analyzes the market assuming a discrete choice utility model and estimating a nested logit. Using consumer level data, she is able to estimate plausible substitution patterns across available automobile varieties. Berry, Levinsohn and Pakes (1995) develop a random coefficients logit model that effectively estimates the demand system for autos in the absence of consumer specific data.

${ }^{12}$ There is a comparable discussion in Appendix B of Feenstra (2004)'s Advanced International Trade.
} 
In order to quantify the bias from neglecting variety change when calculating these equations, Feenstra (1994) manipulates relative unit cost requirements into an aggregate price index free of taste parameters, assuming $b_{g v t}=b_{g v t-1}$ for $v \in I_{g} \subseteq\left(I_{g t} \cap I_{g t-1}\right), I_{g} \neq \varnothing$. We define the exact price index, $\pi$, as a function of price, cost minimizing quantity, and variety vectors,

$$
\begin{aligned}
\frac{\phi^{X}\left(I_{g t}, \mathbf{b}_{g t}\right)}{\phi^{X}\left(I_{g t-1}, \mathbf{b}_{g t-1}\right)} & =\pi^{X}\left(\mathbf{p}_{g t}, \mathbf{p}_{g t-1}, \mathbf{x}_{g t}, \mathbf{x}_{g t-1}, \mathbf{I}_{g}\right) \\
& =P^{X}\left(\mathbf{p}_{g t}, \mathbf{p}_{g t-1}, \mathbf{x}_{g t}, \mathbf{x}_{g t-1}, \mathbf{I}_{g}\right)\left(\frac{\lambda_{g t}}{\lambda_{g t-1}}\right)^{\frac{1}{\sigma_{g}-1}}
\end{aligned}
$$

Further, by Sato (1976) and Vartia (1976),

$$
P^{X}\left(\mathbf{p}_{g t}, \mathbf{p}_{g t-1}, \mathbf{x}_{g t}, \mathbf{x}_{g t-1}, \mathbf{I}_{g}\right) \equiv \prod_{v \in I_{g}}\left(\frac{p_{g v t}}{p_{g v t-1}}\right)^{w_{g v t}\left(I_{g}\right)}
$$

is the geometric mean of particular variety price changes, where the ideal log-change weights are

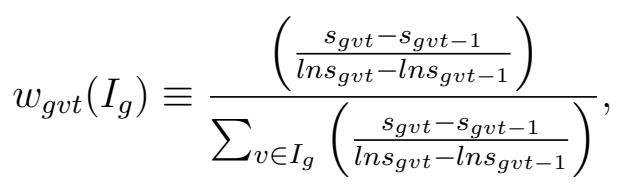

which is the harmonic mean of the variety cost shares $s_{g v r}=\frac{p_{g v r} x_{g v r}}{\sum_{v \in I_{g}} p_{g v r} x_{g v r}}$ for $r=t, t-1$.

The bias generated by neglecting new and disappearing varieties on the conventional price index, $P^{X}$, is quantified by the $\lambda$ ratio raised to the power of $\frac{1}{\sigma_{g}-1}$, which we will call the corrected $\lambda$ ratio. The $\lambda$ ratio captures the net gain or loss of varieties by value, as

$$
\lambda_{g r} \equiv \frac{\sum_{v \in I_{g}} p_{g v r} x_{g v r}}{\sum_{v \in I_{g r}} p_{g v r} x_{g v r}} \quad \text { for } r=t-1, t
$$

where $v \in I_{g}=\left(I_{g t} \cap I_{g t-1}\right)$ and $g \in G$. In time periods where the expenditure on new varieties in the current period exceeds that of disappearing varieties from the previous period, the $\lambda$ ratio scales down the exact price index. Intuitively, consumers gain from an excess value of new varieties, and lose from an excess of disappearing varieties. The corrected $\lambda$ ratio adjusts the period by period net value of new and disappearing varieties by the substi- 
tutability of these varieties. For large $\sigma_{g}$, varieties are highly substitutable, and increasing or decreasing the set available to consumers has little effect on the exact price index. This is demonstrated clearly through the corrected $\lambda$ ratio, which approaches 1 regardless of the net variety change for surviving goods as $\sigma_{g} \rightarrow \infty$.

\subsubsection{Aggregate Price Index}

Broda and Weinstein (2006) expand upon the exact price index for the subutility function derived by Feenstra (1994) and show that one can easily aggregate price indexes across many goods into an aggregate exact import price index which can be written as,

$$
\Pi^{M}\left(\mathbf{p}_{g t}, \mathbf{p}_{g t-1}, \mathbf{x}_{g t}, \mathbf{x}_{g t-1}, \mathbf{I}_{g}\right)=\prod_{g \in G} P_{g}^{M}\left(I_{g}\right)^{w_{g t}}\left(\frac{\lambda_{g t}}{\lambda_{g t-1}}\right)^{\frac{w_{g t}}{\sigma_{g}-1}}
$$

The weights, $w_{g t}$, are ideal log-change at the goods level. This second tier price index is dual for domestic varieties. Thus, the aggregate market price index is,

$$
\Pi=\left(\Pi^{D}\right)^{w_{t}^{D}}\left(\Pi^{X}\right)^{w_{t}^{M}}
$$

The exponents are ideal log-change weights at the good origin level. Due to the lack of domestic data detailing variety change, Broda and Weinstein (2006) cannot calculate an overall price index as we have defined. They instead focus on the effect of varieties on the aggregate import price index. ${ }^{13}$ Thus, for direct comparisons we will focus on the aggregate import price index using various assumptions about our market level data, since our import data are deficient in the same way.

\footnotetext{
${ }^{13}$ As a robustness check, Broda and Weinstein (2006) relax the assumption of Krugman (1979), which specifies that the number of domestic varieties are unassailable from competition with new foreign varieties. They adopt a model from Helpman and Krugman (1985) which suggests, for their estimates, it is appropriate to reduce their welfare gains to U.S. consumers from imported varieties by $16 \%$. While we will not be able to estimate if this is the correct scaling factor to account for displaced domestic varieties, we do expand upon the understanding of variety change in the domestic sector.
} 


\section{3. $\quad$ Estimating $\sigma$}

To implement price index calculations in Equation 9, we need consistent estimates of the elasticity of substitution for each variety. Following Feenstra (1994), the underlying demand in first differences for each variety can be written as,

$$
\begin{aligned}
\Delta \ln \left(s_{g v t}\right) & =\varphi_{g t}-\left(\sigma_{g}-1\right) \Delta \ln \left(p_{g v t}\right)+\epsilon_{g v t}, \quad \text { where }, \\
\varphi_{g t} & =\left(\sigma_{g}-1\right) \ln \left[\frac{\phi_{g t}^{X}\left(b_{t}\right)}{\phi_{g t-1}^{X}\left(b_{t-1}\right)}\right]
\end{aligned}
$$

is a time-good specific random shock driven by the random taste parameter, $b_{t}$. The variety specific random shock, $\epsilon_{\text {gvt }}=\Delta \ln \left(b_{\text {gvt }}\right)$, is driven by the random tastes of consumers across varieties.

We assume producers compete in monopolistically competitive markets for their varieties such that prices in first differences are,

$$
\begin{aligned}
\Delta l n\left(p_{g v t}\right) & =\psi_{g t}+\frac{\omega_{g}}{1+\omega_{g}} \Delta \ln \left(s_{g v t}\right)+\delta_{g v t}, \quad \text { where } \\
\psi_{g t} & =-\omega_{g} \Delta \ln \left(\frac{\sum_{v \in I_{g t}} p_{g v t} x_{g v t}}{1+\omega_{g}}\right)
\end{aligned}
$$

captures time-good specific shocks to production. The inverse supply elasticity for each good is $\omega_{g} \geq 0 .{ }^{14}$ Random technology changes in the production of each variety, $\nu_{g v t}$ manifest themselves through $\delta_{g v t}=\Delta \ln \left(\frac{\nu_{g v t}}{1+\omega_{g}}\right)$. It is vital to our identification strategy that variety specific shocks to demand and supply be independent, thus we assume $E\left[\epsilon_{g v t} \delta_{g v t}\right]$.

Choosing a reference variety, $k \in V$ that is present in each period of our sample, we can difference our demand and supply equations, yielding,

$$
\begin{aligned}
& \Delta^{k} \ln \left(s_{g v t}\right)=-\left(\sigma_{g}-1\right) \Delta^{k} \ln \left(p_{g v t}\right)+\epsilon_{g v t}^{k} \\
& \Delta^{k} \ln \left(p_{g v t}\right)=\frac{\omega_{g}}{1+\omega_{g}} \Delta^{k} \ln \left(s_{g v t}\right)+\delta_{g v t}^{k} .
\end{aligned}
$$

Variables denoted with a superscript $k$, are differenced from the reference good, such as

\footnotetext{
${ }^{14}$ This implicitly assumes that the supply elasticity is identical across varieties.
} 
$\epsilon_{g v t}^{k}=\epsilon_{g v t}-\epsilon_{g k t}$. Independence of our errors implies $E\left[\epsilon_{g v t}^{k} \delta_{g v t}^{k}\right]$, which we utilize to obtain the estimating equation

$$
\begin{aligned}
& \Delta^{k} \ln \left(p_{g v t}\right)^{2}=\theta_{1} \Delta^{k} \ln \left(s_{g v t}\right)^{2}+\theta_{2} \Delta^{k} \ln \left(p_{v c t}\right) \Delta^{k} \ln \left(s_{g v t}\right)+u_{g v t} \quad \text { where, } \\
& u_{g v t}=\frac{\epsilon_{g v t}^{k} \delta_{g v t}^{k}}{\sigma_{g}-1}, \quad \theta_{1}=\frac{\omega_{g}}{\left(1+\omega_{g}\right)\left(\sigma_{g}-1\right)^{2}}, \quad \text { and } \quad \theta_{2}=\frac{1-\omega_{g}\left(\sigma_{g}-2\right)}{\left(1+\omega_{g}\right)\left(\sigma_{g}-1\right)},
\end{aligned}
$$

by multiplying the differenced error terms and dividing by $\sigma-1$. Endogeneity is apparent, as the error term in our estimating equation is comprised of the error terms of the regressands. Feenstra (1994) demonstrates that by taking advantage of the panel nature of the data one can control for this endogeniety by using variety specific dummies as instruments. This will produce consistent and efficient estimates of $\theta_{1}$ and $\theta_{2}$ as long as,

$$
\frac{\sigma_{\epsilon, i}^{2}+\sigma_{\epsilon, k}^{2}}{\sigma_{\epsilon, j}^{2}+\sigma_{\epsilon, k}^{2}} \neq \frac{\sigma_{\delta, i}^{2}+\sigma_{\delta, k}^{2}}{\sigma_{\delta, j}^{2}+\sigma_{\delta, k}^{2}} \text { for some countries } i \neq k \text { and } j \neq k
$$

From the consistent estimates of $\theta_{1}$ and $\theta_{2}$, we can calculate

$$
\hat{\rho}_{g}= \begin{cases}\frac{1}{2}+\left(\frac{1}{4}-\frac{1}{4+\frac{\hat{\theta}_{2}}{\hat{\theta}_{1}}}\right)^{\frac{1}{2}} & \text { for } \theta_{1}, \theta_{2}>0 \\ \frac{1}{2}-\left(\frac{1}{4}-\frac{1}{4+\frac{\hat{\theta}_{2}}{\hat{\theta}_{1}}}\right)^{\frac{1}{2}} & \text { for } \theta_{1}>0 \text { and } \theta_{2}<0\end{cases}
$$

where $\rho_{g} \equiv \frac{\omega_{g}\left(\sigma_{g}-1\right)}{1+\sigma_{g} \omega_{g}}$, is the correlation between shifts in the demand curve and the resulting change in equilibrium prices. The elasticity of substitution for each good is then,

$$
\hat{\sigma}_{g}=1+\left(\frac{2 \hat{\rho}_{g}-1}{1-\hat{\rho}_{g}}\right) \frac{1}{\hat{\theta}_{2}} .
$$

In the case where $\theta_{g}<0$, theoretically feasible values for $\rho_{g}$ and $\sigma_{g}$ generally cannot be computed. ${ }^{15}$ As proposed by Broda and Weinstein (2006), we use a grid search over the set of economically feasible values of $\sigma_{g}$ and $\rho_{g}$ to minimize the GMM objective function implied by

\footnotetext{
${ }^{15}$ It is possible to obtain feasible estimates under relatively stringent conditions. Feenstra (1994) discusses these conditions, of which none of our estimates satisfy, and demonstrates a case where feasible estimates are obtained using these equations with $\theta_{1}<0$.
} 
the IV estimation. Explicitly, we choose values $\sigma_{g} \in[1.05,100.05]$ at equally spaced intervals of .075 and 100 equal intervals of $\rho_{g}\left[0, \frac{\sigma_{g}-1}{\sigma_{g}}\right)$ to minimize $G^{*}\left(\rho_{g}, \sigma_{g}\right)^{\prime} W G^{*}\left(\rho_{g}, \sigma_{g}\right)$, where $G^{*}\left(\rho_{g}, \sigma_{g}\right)$ is the sample analog of the moment condition, $G\left(\rho_{g}, \sigma_{g}\right)=E_{t}\left[u_{g v t}\right]=0, \forall v$.

The use of unit values in place of prices is inherent to import data. Feenstra (1994) demonstrates that including a constant when estimating Equation 11, solves the problem of known measurement error bias from using unit values. We will also include a constant when we estimate using market data, however we expect measurement error to be less severe since we observe Manfacturer's Suggested Retail Prices (MSRPs), which are likely closer to actual transaction prices than unit values. ${ }^{16}$

\section{Empirical Analysis}

We begin our empirical analysis with a comparison of estimated new variety effects using the traditional import data versus using the market data. As described in the previous section, this involves first estimating elasticities of substitution separately by good for each data set following Feenstra (1994) and calculating conventional price indexes and exact price indexes (which correct for net new variety change) by good. Then, following Broda and Weinstein (2006), we construct aggregate price index changes for all automobile goods in each data set, part of which separates out the change in the aggregate price index due to new varieties. This can then also be easily related to welfare effects due to new varieties. As we will see, there are significant differences across the data sets in the estimated effects of new varieties.

After these comparisons, we next explore a few issues that one can only address using our market data sample. First, unlike import data, we have data on domestic varieties and can compare the patterns of net variety change on prices across domestic and import varieties. Second, we have information on ownership of varieties in our market data. Therefore, we can examine the effect of new variety change on U.S. welfare from "foreign-owned" varieties, rather than simply from imports, some of which may be outsourced domestic-owned varieties.

\footnotetext{
${ }^{16}$ Broda and Weinstein (2006)'s propose an optimal weighting scheme assuming that the measurement error in unit values is inversely related to the volume of imports. We expect the same relationship to apply to our market level data for an additional reason. We use the MSRP of the base model as our price measure, which will be biased down for units sold with expensive options, and biased up in the presence of dealer discounts. However, there is anecdotal evidence that high sales vehicles tend to have transaction prices closer to the MSRP of the base model than vehicles with fewer sales.
} 
Finally, we examine whether calculated variety change and its effects are sensitive to the time interval used.

\subsection{Comparison between import and market data}

We begin our comparison by first estimating elasticities of substitution for goods for each data sample and then calculating annual price index changes by good which are comprised of pure price changes of continuing models and equivalent price changes due to net variety change. Columns 2 through 5 of Table 4 report relevant estimates and constructed measures by goods when using our import data.

Column 2 reports our estimates of elasticities of substitution by HS10 goods. There is substantial heterogeneity in these estimates across goods with a weighted average mean elasticity of substitution around 11.4 and a median of 7 . There are a couple outliers with large estimated elasticities, but these are for goods with obviously low import activity given the weighted average elasticity.

We then use these estimates along with our price, quantity, entry, and exit data by variety to calculate annual changes in the exact price index for each good from 1990 through 2005, which can be decomposed into the change in the conventional price index multiplied by the corrected $\lambda$ ratio that translates net variety change into effective price index changes. We normalize the price indexes and corrected $\lambda$ ratios to be 1 for each good in our base year, 1990, and cumulate these changes over our sample.

Columns 3, 4, and 5 of Table 4 show the value of the conventional price index, the corrected $\lambda$ term in the final year, and the exact price index for the final year of our sample, 2005, for each good. For example, a value of 2 in the final year means that price index of the good has doubled over our sample. Also, recall that the corrected $\lambda$ ratio measures how much the net variety change scales up or down the exact price index relative to the conventional price index with values below 1.000 indicating net new variety change.

Overall, there is modest evidence of net variety entry with a weighted-average corrected $\lambda$ ratio of 0.977 and a median of 0.998 across goods in Table 4 . This represents significantly less net variety change than that found by Broda and Weinstein (2006), who report a median value of 0.95 for the same measure across all imported products over the 1990-2001 period. 
This finding is consistent with the low turnover of automobile varieties we find in the import data, as discussed earlier. ${ }^{17}$ As a result of little new net variety change, the differences in the exact price index over the conventional price index are small on average across products.

While these goods-level comparisons are interesting, the true aggregate picture of net variety change effects on prices across the automobile sector is obtained aggregating across goods following Equation 9. These calculations suggest more variety change with an aggregate corrected $\lambda$ ratio of 0.959 over our 1990-2005 sample of automobile goods. Thus, while the conventional price index went up $65.7 \%$ over our sample of imported automobiles, the exact price index (controlling for net variety change) only goes up 59.0\%. This translates into a ratio of the exact price index to the conventional price index of 0.960 which compares to Broda and Weinstein (2006) finding of 0.917 for the same ratio across all imported products in their 1990-2001 sample. These are our baseline measures using the import data and associate HS10 goods definitions.

We next apply the same methodology to generate analogous results using our market data and market-based goods definitions. The latter columns of Table 4 show the rough concordance between the import (HS10) goods and our market goods categories. It is clear that the concordance is far from a one-to-one mapping and that this will be one source of differences in estimates across the two samples.

Table 5 provides substitution elasticities, the conventional price index changes, the corrected $\lambda$ ratio changes, and the exact price index changes over our sample of goods using our market data. ${ }^{18}$ We cannot make separate estimates for a couple market goods (Subcompact and Van) using our market data because there is no single variety that survives our entire sample to serve as a reference variety. Therefore, we combine the data for subcompact automobiles with compact automobiles, and vans with minivans.

\footnotetext{
${ }^{17} \mathrm{HS} 10$ good 8703230036 is an outlier with a very large increase in its exact price index and corrected $\lambda$ ratio. This stems from a very large exit of varieties during one of our sampleÕs earlier years. We conjecture that there may have been an incorrect HS10 classification in this early year, which was right after the U.S. switched to the HS method of categorizing import goods. Such an artificial change in HS10 classification would then show up as a large exit in our data. Since this particular HS10 good accounts for a miniscule share of U.S. automobile imports, it has essentially no impact on our aggregate price index and welfare calculations.

${ }^{18}$ For comparison, we also provide these same measures using our import data estimations and calculations by concording the import (HS10) goods into our market goods definitions. Namely, we aggregate for each market good by constructing weighted averages across the relevant import (HS10) goods using ideal weights.
} 
From Table 5, estimated elasticities of substitution tend to be slightly higher across our market-based goods (11.562) than for the import-based goods (11.382). ${ }^{19}$ These higher substitution elasticities for the market data sample are even more notable given that marketbased goods categories only number ten, while the import goods (HS10) for automobiles numbers 28. This suggests that our market-based goods definitions are better at assigning varieties of the same good than the import-based HS10 good definitions.

The average conventional price change across the goods in Table 5 is about $64 \%$ using the market data. This represents a smaller average price increase than for the import goods in Table 4 which was about $75 \%$. While this difference is interesting, the interpretation is not clear since our market prices are at the retail level, while the import prices are border prices and most likely correspond best to wholesale prices. ${ }^{20}$

The corrected $\lambda$ ratio change is significantly lower on average across goods using the market data than for the import data, suggesting more net variety change. Thus, the market data suggest more significant net variety gains than the import data, and this means a greater average difference between the exact and conventional price indexes.

These same results hold when we properly aggregate across our goods using the method of Broda and Weinstein (2006) and characterized in Equation 9. The first two rows of Table 6 compare the import and market datasets in their estimates of the relevant measures of aggregate automobile price and net variety changes. There are large differences. The primary difference of interest is that the corrected $\lambda$ ratio across all automobile products using the market data and goods definitions is 0.922 , which represents about $90 \%$ more effective variety change than our benchmark using the import data and goods definitions (0.959). Assuming the same functional forms as Broda and Weinstein (2006), this means that the welfare effect from net new variety change is also about twice as large using our

\footnotetext{
${ }^{19}$ We estimate Equation 11 many times, so for the sake of brevity we do not present the individual coefficient estimates. However, the presence of measurement error follows our previous predictions; estimates of our constant term suggest measurement error plays a significant role in our import data, but has little distinguishable effect in our market data.

${ }^{20} \mathrm{An}$ obvious possibility is that retail profit margins have fallen over our sample. However, there are also measurement issues in both price terms where systematic changes in those errors over time could account for the difference. Since this is not the focus of this paper, we do not pursue the issue further.
} 
market data as when using our import data. ${ }^{21}$

Figure 1 provides further information on the differences between the import and market datasets estimates of net new variety change and its effects on the exact price index, by showing the annual changes over our sample. Panel A of Figure 1 shows the raw variety change over time captured by the simple $\lambda$ ratio, where declines in the ratio indicate net new variety gains. The market data show substantially more net new variety gains over time, though these differences are muted when one views the corrected $\lambda$ ratio shown in Panel B which accounts for the degree of substitutability between varieties for each good. As one can see, the latter years of our sample are when the difference in net new variety changes between the two data sets has become most pronounced. Panels $\mathrm{C}$ and $\mathrm{D}$ of Figure 1 show the annual changes in the conventional and exact price indexes for automobiles for each data set. Two clear differences emerge. First, while the market-based price indexes rise at a fairly consistent rate over the sample, the import-based price indexes show relatively flat price changes in the beginning and end of the sample with a relatively large annual price increases from 1994 to 2000. This observation may be attributable to consumption smoothing practices by retailers that cannot be gleaned from unit values, or a pronounced effect of measurement error in our import data contributing to the relatively drastic price swings calculated from these data. Second, and of more interest for this paper, the exact price index shows much lower price increases relative to the conventional price index (due to net new variety change) for the market data set than for the import data set.

In summary, there appear to be two opposing biases from the import-based goods (mis)classifications. First, the Armington assumption on varieties hides significant churning of varieties, which in this case also means it misses a significant amount of net new variety change and biases one toward finding lower gains from new imported varieties. On the other hand, to the extent that import goods classifications (HS10) deviate from (true)

\footnotetext{
${ }^{21}$ As Broda and Weinstein (2006) shows, welfare gains from foreign varieties in this model can be calculated as a compensating variation that is equal to a scaling factor multiplied with the inverse of the conventional price index. This scaling factor is equal to the inverse of the weighted product of the corrected $\lambda$ ratios across goods, raised to the share of foreign varieties in total consumption. When corrected $\lambda$ ratios and price indexes are reasonably close to one and the share of foreign varieties in total consumption is greater than zero, then the compensating variation will roughly correlate directly to how far the corrected $\lambda$ ratios are from one. For example, the inverse of 0.922 is 1.085 , which is a scaling factor that will roughly lead to twice the increase from a scaling factor of $1.043 \mathrm{Ð}$ the inverse of 0.959 .
} 
market-based classifications, elasticities of substitution will be biased downward, which will bias one toward finding a greater effect of net imported variety change on prices and welfare in the import data. In our case, we find that the former effect outweighs the latter effect in significant fashion, creating a bias that underestimates the price and welfare effects of imported variety change by about half.

\subsection{Comparing Effects Across Domestic and Import Varieties}

Past studies of the effects of product variety do not have data on domestic varieties. This first means that they cannot estimate and compare the impact of net variety change on prices stemming from domestic sources versus import sources. In contrast, our market data allow us to easily calculate these measures for domestic varieties, which we do and report in Row 3 of Table 7 . As one might expect given the declining market shares of U.S. manufacturers in the U.S. automobile market, price increases are larger and net variety effects are smaller for domestic varieties over our sample as compared to what is found for import varieties. We estimate that the effect of net variety change on prices is twice as large for import varieties as from domestic varieties. (0.922 is 0.078 points below a scale factor of 1.000 , whereas 0.962 is only 0.038 points below 1.000 )

\subsection{Accounting for Foreign Affiliate Production}

A country most likely cares most about the gains they get from new varieties from foreign sources, not just those foreign varieties that are imported. As a result, accounting for foreign affiliate activity is very important in understanding the gains to an economy from foreign sources. Since the early 1980s foreign automobile manufacturers have located substantial production in the United States, often introducing new varieties through foreign affiliate production, not imports. In this way, a focus on import data alone could substantially underestimate the gains to U.S. consumers from foreign varieties. Relatedly, U.S. automobile manufacturers have outsourced some production to foreign affiliates (most often in NAFTA partner countries) over the past decades as well. These U.S. varieties may then get erroneously assigned as "foreign" because they are part of U.S. imports, and may lead estimates of new variety gains from foreign imports to be overestimated. 
Our market data allows us to easily disentangle foreign from U.S. varieties because we have information on both the ownership and production location of an automobile variety. Thus, as an alternative to the import/domestic distinction that is determined by production location, we split our data by ownership into domestic-owned versus foreign-owned varieties. Domestic-owned varieties include any varieties produced by a U.S. auto manufacturer, regardless of whether it was produced in the U.S. or outsourced to an affiliate abroad and imported back into the U.S. Foreign-owned varieties include both those imported into the U.S. and those produced by foreign affiliates in the U.S.

Table 8 provides estimates of substitution elasticities, price indexes, and corrected lambda ratios by goods for our samples of domestic and foreign-owned varieties, while the last rows of Table 6 provide the price indexes and corrected lambda ratio for automobiles when we appropriately aggregate up over these goods. The results contrast significantly with our previous estimates separating varieties into "imports" and "domestic". While the estimated elasticities of substitution are generally in the same range and standard price indexes almost identical, the corrected lambda ratios suggest significantly more net variety change when separating varieties into domestic- and foreign-owned. The corrected lambda ratio for foreign-owned is just 0.871, which translates into about a $70 \%$ larger impact of net variety change on the standard price index and, thus, similar differences in welfare gains, than from imported varieties alone. Interestingly, the estimated effect of net variety change from domestic-owned varieties is also significantly larger relative to the previously defined "domestic" (or non-imported) category as well.

In summary, it is clear that defining varieties by ownership, rather than by production location, has a significant effect on the estimates. To the extent that ownership is the correct way to classify foreign versus domestic varieties, classification by location (i.e., imports versus non-imports) significantly underestimates the actual welfare gains experienced by U.S. consumers from foreign varieties of automobiles over our sample. This certainly means that the bias from not including foreign-owned, domestic-produced varieties as foreign substantially outweighs the bias from including domestic-owned foreign-produced (or outsourced) 
varieties as foreign. ${ }^{22}$

\subsection{Robustness of Results to the Time Interval of Calculations}

Given annually recorded data, it is natural to make calculations of net variety changes on an annual basis. However, this implicitly assumes that new varieties achieve their equilibrium market share within the year of introduction. Alternatively, first-year market shares of new varieities may be quite different from their ultimate equilibrium market share. For example, it may take consumers significant time to become fully informed about a new variety. This may be particularly true in the automobile sector with sophisticated products for which product reviews and reliability figures take time to gather and observe. If consumers are cautious in their purchase of new varieties for these reasons, first-year market shares may be below their eventual equilibrium market share and calculation of the share of net new variety consumption relative to existing varieties may very well underestimate the true impact of new varieties on the marketplace. ${ }^{23}$ There are also reasons why market shares of exiting varieties may not be true representations of their equilibrium market share. For example, an automobile manufacturer may simply close down production and sales of an existing variety in the middle of its final year, leading to a much lower market share than if the variety had been available for the entire year.

As a simple way to examine the sensitivity of our estimates to these considerations, we alternatively calculate price indexes and net variety change measures (corrected $\lambda$ indexes) using three-year intervals of our data. For example, rather than calculate net new variety and price index changes for each year from 1990 to 1993, we only calculate the three-year change over this period. As a result, new varieties that occur in the early part of the threeyear period will have had time to reach their equilibrium market share. Obviously this is not a perfect solution, as new varieties in the last years of the interval may not have had time to reach their equilibrium market share, but it will at least give some indication of the

\footnotetext{
${ }^{22}$ We have done separate estimates where we only control for one of these channels of bias at a time and find that the bias from not taking into net variety change from U.S. outsourcing is very small, whereas the bias from not taking into account variety change introduced by foreign affiliates is therefore very large.

${ }^{23}$ It is certainly possible that first-year market shares could be larger than equilibrium market shares causing the effects of net variety change to be overestimated. For example, automobile manufacturers may devote much more advertising expenditures to new varieties distorting their "true" market share.
} 
potential bias. This procedure would also miss significant variety change if varieties often turned over in less than three years. This is not an issue with the automobile data as new models almost always remain in the market for at least three years.

Table 9 provides calculations when using three-year intervals of our data for the same scenarios reported in Table 6 using annual intervals to make calculations. Our calculations of price indexes and net variety changes using our market-based dataset are virtually identical across the two tables. Figure 2 repeats the exercise undertaken in Figure 1, and yields qualitatively similar outcomes. This speaks to the robustness of our results and suggests that first-year new variety market shares and last-year variety market shares are representative of their equilibrium market shares. We also find in the raw data that the average market share of new varieties in their first year is not significantly different from their average market share in subsequent years.

\section{Conclusion}

The effects of product variety have been important to international trade economists for decades, yet measuring varieties remains problematic. This paper revisits important recent work estimating the impact of variety change from foreign sources on domestic prices and welfare. Using detailed market-based data on the U.S. automobile sector, we show significant biases resulting from the use of HS product codes to define goods and the Armington assumption used to assign varieties. Compared to our market-based automobile dataset, HS codes often lumped quite dissimilar products into the same good classification, which biases elasticities of substitution downward. On the other hand, the Armington assumption hides substantial net variety change. On net, our market-based estimates suggest the effect of net variety change from automobile imports on U.S. welfare for the 1990-2006 period was almost twice as large as that estimated by the typical trade (HS) data and Armington-defined varieties. Taking into account net variety change by affiliates of foreign firms (something the import data cannot identify) further increases these welfare effects by about an additional $70 \%$.

While our paper examines the automobile market, we have examined a number of issues that likely affect the estimation of new variety effects for all (differentiated) products. First, 
HS10 goods codes may not correspond very well with market-based goods definitions, which will then likely bias substitution elasticities downward and inflate the estimated impact of new variety change. Second, the Armington assumption can hide true variety churning (as measured by market share), but may also artificially inflate churning of varieties measured as simple counts because import data reflect consumer's purchases of products foreign country that is not the location of production. Finally, using only import data ignores the effects of variety change from foreign affiliate activity that we find to be a significant source of net new variety change in our data. Recent statistics show foreign affiliate sales in the U.S. to be roughly similar in size to U.S. imports for not only the motor vehicle sector, but also for total manufactured goods. 


\section{References}

Anderson, S. P., dePalma, A. and Thisse, J.-F. (1992), Discrete Choice Theory of Product Differentiation, The MIT Press.

Berry, S., Levinsohn, J. and Pakes, A. (1995), 'Automobile Prices in Market Equilibrium', Econometrica 63(4), pp. 841-90.

Berry, S., Levinsohn, J. and Pakes, A. (1999), 'Voluntary Export Restraints on Automobiles: Evaluating a Strategic Trade Policy', American Economic Review 89(3), pp. 400-30.

Broda, C. and Weinstein, D. (2006), 'Globalization and the Gains from Variety', Quarterly Journal of Economics 121(2), pp. 541-85.

Feenstra, R. C. (1994), 'New Product Varieties and the Measurement of International Prices', The American Economic Review 84(1), pp. 157-177.

Feenstra, R. C. (2004), Advanced International Trade: Theory and Evidence, Princeton University Press, Princeton, N.J.

Goldberg, P. K. (1995), 'Product Differentiation and Oligopoly in International Markets: The Case of the U.S. Automobile Industry', Econometrica 63(4), pp. 891-951.

Goldberg, P. K. and Verboven, F. (2005), 'Market Integration and Convergence to the Law of One Price: Evidence from the European Car Market', Jounal of International Economics 65(1), pp. 49-73.

Helpman, E. and Krugman, P. R. (1985), Market structure and foreign trade : increasing returns, imperfect competition, and the international economy / Elhanan Helpman and Paul R. Krugman, MIT Press, Cambridge, Mass. :.

Imbs, J. and Mejean, I. (2008), 'Elasticity Optimism', mimeo UC Berkeley .

Krugman, P. R. (1979), 'Increasing returns, monopolistic competition, and international trade', Journal of International Economics 9(4), pp. 469-479. 
Petrin, A. (2002), 'Quantifying the Benefits of New Products: The Case of the Minivan', Journal of Political Economy 110(4), pp. 705-29.

Rauch, J. (1999), 'Neworks versus Markets in International Trade', Jounal of International Economics 48(1), pp. 7-37.

Sato, K. (1976), 'The Ideal Log-Change Index Number', Review of Economics and Statistics 58(2), pp. 223-228.

Vartia, Y. O. (1976), 'Ideal Log-Change Index Numbers', Scandinavian Journal of Statistics 3, pp. 121-126.

Verboven, F. (1996), 'International Price Discrimination in the European Car Market', RAND Journal of Economics 27(2), pp. 240-268. 
Table 1: Varieties in Market Data

\begin{tabular}{|c|c|c|c|c|c|c|}
\hline \multirow[b]{2}{*}{ Good } & \multicolumn{3}{|c|}{ Total Distinct Models } & \multicolumn{3}{|c|}{ Average Models per Year } \\
\hline & Foreign & Domestic & Pooled* & Foreign & Domestic & Pooled* \\
\hline \multicolumn{7}{|l|}{ Cars } \\
\hline Midsize & 48 & 38 & 74 & 20 & 17 & 35 \\
\hline Compact & 42 & 33 & 58 & 16 & 15 & 26 \\
\hline Sport & 33 & 12 & 43 & 14 & 5 & 18 \\
\hline Fullsize & 24 & 24 & 42 & 11 & 12 & 22 \\
\hline Subcompact & 33 & 9 & 36 & 12 & 5 & 14 \\
\hline Sport Compact & 11 & 8 & 18 & 5 & 4 & 9 \\
\hline Executive & 14 & 0 & 14 & 6 & 0 & 6 \\
\hline Compact Executive ${ }^{\S}$ & 10 & 1 & 10 & 5 & 1 & 5 \\
\hline Grand Tourer & 7 & 2 & 9 & 4 & 1 & 4 \\
\hline Luxury & 4 & 0 & 4 & 3 & 0 & 3 \\
\hline Electric $^{\dagger}$ & 1 & 0 & 1 & 1 & 0 & 1 \\
\hline Supercar ${ }^{\dagger}$ & 1 & 0 & 1 & 1 & 0 & 1 \\
\hline \multicolumn{7}{|l|}{ SUVs } \\
\hline SUV & 38 & 45 & 74 & 16 & 21 & 35 \\
\hline Crossover SUV§ & 19 & 7 & 26 & 10 & 5 & 14 \\
\hline $\mathrm{SUT}^{\dagger}$ & 0 & 4 & 4 & 0 & 3 & 3 \\
\hline Station Wagon ${ }^{\dagger}$ & 0 & 1 & 1 & 0 & 1 & 1 \\
\hline \multicolumn{7}{|l|}{ Trucks } \\
\hline Pickup & 12 & 22 & 26 & 6 & 12 & 14 \\
\hline Medium Duty ${ }^{\dagger}$ & 0 & 1 & 1 & 0 & 1 & 1 \\
\hline \multicolumn{7}{|l|}{ Vans } \\
\hline Minivan & 14 & 19 & 28 & 6 & 11 & 14 \\
\hline Van & 8 & 6 & 12 & 4 & 4 & 6 \\
\hline
\end{tabular}

Notes:* Models produced both domestically and abroad are not considered distinct, thus Total does not necessarily equal the sum of Domestic and Foreign Models. ${ }^{\dagger}$ Cannot satisfy the requirements of a reference model, and do not easily fit in another class, thus not included in our estimation. ${ }^{\S}$ Insufficient reference variety, however these classes are extremely comparable to other goods. 
Table 2: Varieties in Import Data

\begin{tabular}{|c|c|c|c|c|c|c|c|c|c|}
\hline \multicolumn{2}{|r|}{ Good } & \multicolumn{2}{|c|}{ Interior $\left(f t^{3}\right)$} & \multicolumn{2}{|c|}{ Cylinders } & \multicolumn{2}{|c|}{ Cyl Vol (cc) } & \multicolumn{2}{|c|}{ Varieties } \\
\hline HS10 & Description & Min & Max & Min & Max & Min & Max & Total & Average \\
\hline 8703210000 & Pass Vehicle Spark Ignition & \multicolumn{2}{|c|}{ NESOI } & \multicolumn{2}{|c|}{ NESOI } & & 1000 & 43 & 24 \\
\hline 8703220000 & Pass Vehicle Spark Ignition & \multicolumn{2}{|c|}{ NESOI } & \multicolumn{2}{|c|}{ NESOI } & 1000 & 1500 & 32 & 18 \\
\hline $8703230010^{\dagger}$ & Pass Vehicle Spark Ignition & \multicolumn{2}{|c|}{ NESOI } & \multicolumn{2}{|c|}{ NESOI } & 1500 & 3000 & 11 & 5 \\
\hline 8703230022 & Wagon or Vans: Height under $160 \mathrm{~cm}$ & \multicolumn{2}{|c|}{99} & & 4 & 1500 & 3000 & 11 & 5 \\
\hline 8703230024 & Wagon or Vans: Height under $160 \mathrm{~cm}$ & 99 & 109.5 & & 4 & 1500 & 3000 & 13 & 4 \\
\hline 8703230026 & Wagon or Vans: Height under $160 \mathrm{~cm}$ & 109.5 & 120 & & 4 & 1500 & 3000 & 14 & 4 \\
\hline 8703230028 & Wagon or Vans: Height under $160 \mathrm{~cm}$ & 120 & & & 4 & 1500 & 3000 & 15 & 7 \\
\hline 8703230032 & Wagon or Vans: Height above $160 \mathrm{~cm}$ & & 99 & & 4 & 1500 & 3000 & 17 & 7 \\
\hline $8703230034^{\dagger}$ & Wagon or Vans: Height above $160 \mathrm{~cm}$ & 99 & 109.5 & & 4 & 1500 & 3000 & 14 & 5 \\
\hline 8703230036 & Wagon or Vans: Height above $160 \mathrm{~cm}$ & 109.5 & 120 & & 4 & 1500 & 3000 & 11 & 4 \\
\hline 8703230038 & Wagon or Vans: Height above $160 \mathrm{~cm}$ & 120 & & & 4 & 1500 & 3000 & 16 & 9 \\
\hline 8703230042 & Other: Cars and Pickups & & 85 & & 4 & 1500 & 3000 & 23 & 15 \\
\hline 8703230044 & Other: Cars and Pickups & 85 & 99 & & 4 & 1500 & 3000 & 26 & 19 \\
\hline 8703230046 & Other: Cars and Pickups & 99 & 109.5 & & 4 & 1500 & 3000 & 21 & 18 \\
\hline 8703230048 & Other: Cars and Pickups & 109.5 & 120 & & 4 & 1500 & 3000 & 17 & 13 \\
\hline 8703230052 & Other: Cars and Pickups & 120 & & & 4 & 1500 & 3000 & 17 & 14 \\
\hline 8703230062 & Other: Cars and Pickups & & 99 & 5 & 6 & 1500 & 3000 & 23 & 20 \\
\hline 8703230064 & Other: Cars and Pickups & 99 & 109.5 & 5 & 6 & 1500 & 3000 & 19 & 17 \\
\hline 8703230066 & Other: Cars and Pickups & 109.5 & 120 & 5 & 6 & 1500 & 3000 & 19 & 13 \\
\hline 8703230068 & Other: Cars and Pickups & 120 & & 5 & 6 & 1500 & 3000 & 26 & 18 \\
\hline $8703230072^{\dagger}$ & Other: Cars and Pickups & & 99 & 6 & & 1500 & 3000 & 8 & 4 \\
\hline $8703230074^{\dagger}$ & Other: Cars and Pickups & 99 & 109.5 & 6 & & 1500 & 3000 & 8 & 5 \\
\hline $8703230076^{\dagger}$ & Other: Cars and Pickups & 109.5 & 120 & 6 & & 1500 & 3000 & 12 & 5 \\
\hline $8703230078^{\dagger}$ & Other: Cars and Pickups & 120 & & 6 & & 1500 & 3000 & 13 & 7 \\
\hline $8703240032^{\dagger}$ & Pass Vehicle Spark Ignition & & 85 & & 4 & 3000 & & 10 & 3 \\
\hline $8703240034^{\dagger}$ & Pass Vehicle Spark Ignition & 85 & 99 & & 4 & 3000 & & 8 & 3 \\
\hline $8703240036^{\dagger}$ & Pass Vehicle Spark Ignition & 99 & 109.5 & & 4 & 3000 & & 8 & 4 \\
\hline $8703240038^{\dagger}$ & Pass Vehicle Spark Ignition & 109.5 & 120 & & 4 & 3000 & & 7 & 4 \\
\hline $8703240042^{\dagger}$ & Pass Vehicle Spark Ignition & 120 & & & 4 & 3000 & & 12 & 5 \\
\hline 8703240052 & Pass Vehicle Spark Ignition & & 99 & 5 & 6 & 3000 & & 19 & 12 \\
\hline 8703240054 & Pass Vehicle Spark Ignition & 99 & 109.5 & 5 & 6 & 3000 & & 21 & 11 \\
\hline 8703240056 & Pass Vehicle Spark Ignition & 109.5 & 120 & 5 & 6 & 3000 & & 19 & 14 \\
\hline 8703240058 & Pass Vehicle Spark Ignition & 120 & & 5 & 6 & 3000 & & 25 & 17 \\
\hline 8703240062 & Pass Vehicle Spark Ignition & & 99 & 6 & & 3000 & & 19 & 12 \\
\hline 8703240064 & Pass Vehicle Spark Ignition & 99 & 109.5 & 6 & & 3000 & & 18 & 11 \\
\hline 8703240066 & Pass Vehicle Spark Ignition & 109.5 & 120 & 6 & & 3000 & & 18 & 12 \\
\hline 8703240068 & Pass Vehicle Spark Ignition & 120 & & 6 & & 3000 & & 21 & 16 \\
\hline $8703310000^{\dagger}$ & Pass Vehicle Diesel & & & & $\mathrm{SOI}$ & & 1500 & 18 & 8 \\
\hline 8703320010 & Pass Vehicle Diesel & & & & $\mathrm{SOI}$ & 1500 & 2500 & 22 & 11 \\
\hline 8703330045 & Pass Vehicle Diesel & $\mathrm{NE}$ & & $\mathrm{NE}$ & & 2500 & & 17 & 8 \\
\hline
\end{tabular}

Notes: ${ }^{\dagger}$ Goods are not included in our analysis since there is not a variety that satisfies the requirements of a reference variety during our 1990-2005 sample. NESOI stands for Not Elsewhere Specified Or Included. 
Table 3: Annual Average Variety Change Across Goods

\begin{tabular}{|c|c|c|c|c|c|}
\hline \multirow[b]{2}{*}{ Good } & \multicolumn{2}{|c|}{ Number of } & \multicolumn{2}{|c|}{ Share of Value for } & \multirow{2}{*}{$\begin{array}{c}\text { Total } \\
\text { Value } \\
(\$ \text { Mil })\end{array}$} \\
\hline & $\begin{array}{c}\text { New } \\
\text { Varieties }\end{array}$ & $\begin{array}{c}\text { Exiting } \\
\text { Varieties }\end{array}$ & $\begin{array}{c}\text { New } \\
\text { Varieties }\end{array}$ & $\begin{array}{c}\text { Exiting } \\
\text { Varieties }\end{array}$ & \\
\hline \multicolumn{6}{|l|}{ Import Data (HS10): } \\
\hline 8703210000 & 3.69 & 3.00 & 0.000 & 0.000 & 1843 \\
\hline 8703220000 & 2.38 & 2.13 & 0.000 & 0.000 & 3626 \\
\hline 8703230022 & 1.00 & 1.00 & 0.076 & 0.019 & 159 \\
\hline 8703230024 & 1.31 & 1.31 & 0.020 & 0.051 & 31 \\
\hline 8703230026 & 1.00 & 1.19 & 0.003 & 0.005 & 213 \\
\hline 8703230028 & 1.63 & 1.38 & 0.003 & 0.000 & 2542 \\
\hline 8703230032 & 2.19 & 2.13 & 0.161 & 0.160 & 48 \\
\hline 8703230036 & 0.94 & 1.31 & 0.138 & 0.197 & 39 \\
\hline 8703230038 & 1.69 & 1.81 & 0.026 & 0.061 & 799 \\
\hline 8703230042 & 2.00 & 1.88 & 0.003 & 0.002 & 2851 \\
\hline 8703230044 & 2.06 & 2.00 & 0.002 & 0.000 & 11065 \\
\hline 8703230046 & 1.94 & 1.75 & 0.001 & 0.000 & 18913 \\
\hline 8703230048 & 1.75 & 1.56 & 0.027 & 0.002 & 4242 \\
\hline 8703230052 & 1.94 & 2.06 & 0.000 & 0.035 & 8034 \\
\hline 8703230062 & 2.25 & 1.69 & 0.009 & 0.001 & 6652 \\
\hline 8703230064 & 1.50 & 1.44 & 0.001 & 0.000 & 3984 \\
\hline 8703230066 & 1.88 & 1.88 & 0.001 & 0.001 & 6175 \\
\hline 8703230068 & 2.44 & 2.19 & 0.001 & 0.000 & 9992 \\
\hline 8703240052 & 1.63 & 1.38 & 0.015 & 0.005 & 3186 \\
\hline 8703240054 & 1.81 & 1.63 & 0.006 & 0.003 & 2701 \\
\hline 8703240056 & 1.44 & 1.31 & 0.001 & 0.000 & 18757 \\
\hline 8703240058 & 2.19 & 1.81 & 0.001 & 0.001 & 29402 \\
\hline 8703240062 & 1.38 & 1.25 & 0.046 & 0.000 & 3743 \\
\hline 8703240064 & 1.13 & 1.06 & 0.002 & 0.001 & 1691 \\
\hline 8703240066 & 1.69 & 1.50 & 0.000 & 0.000 & 2719 \\
\hline 8703240068 & 1.50 & 1.19 & 0.000 & 0.000 & 18290 \\
\hline 8703320010 & 2.38 & 1.94 & 0.053 & 0.052 & 291 \\
\hline 8703330045 & 1.63 & 1.25 & 0.017 & 0.028 & 87 \\
\hline Average $\ddagger$ & 1.90 & 1.64 & 0.004 & 0.003 & 13131 \\
\hline \multicolumn{6}{|l|}{ Market Data: } \\
\hline Compact & 2.31 & 2.00 & 0.065 & 0.049 & 36377 \\
\hline Compact Executive & 0.44 & 0.25 & 0.053 & 0.015 & 4432 \\
\hline Executive & 0.31 & 0.63 & 0.046 & 0.051 & 4519 \\
\hline Fullsize & 1.44 & 1.75 & 0.050 & 0.023 & 26283 \\
\hline Grand Tourer & 0.38 & 0.25 & 0.100 & 0.013 & 1639 \\
\hline Luxury & 0.19 & 0.13 & 0.073 & 0.002 & 1333 \\
\hline Midsize & 3.00 & 2.50 & 0.054 & 0.023 & 57976 \\
\hline Minivan & 1.19 & 0.94 & 0.052 & 0.027 & 21820 \\
\hline $\mathrm{PU}$ & 0.88 & 0.75 & 0.035 & 0.016 & 40203 \\
\hline Sport & 1.88 & 1.81 & 0.090 & 0.096 & 6380 \\
\hline Sport Compact & 0.50 & 1.06 & 0.061 & 0.051 & 8217 \\
\hline Subcompact & 1.25 & 2.06 & 0.076 & 0.100 & 3177 \\
\hline SUV & 5.38 & 2.31 & 0.081 & 0.015 & 62570 \\
\hline Van & 0.44 & 0.63 & 0.060 & 0.062 & 6400 \\
\hline Average $\ddagger$ & 2.49 & 1.22 & 0.059 & 0.029 & 40358 \\
\hline
\end{tabular}

Notes: ${ }^{\ddagger}$ Calculated as a weighted average using the ideal log-change weights. 


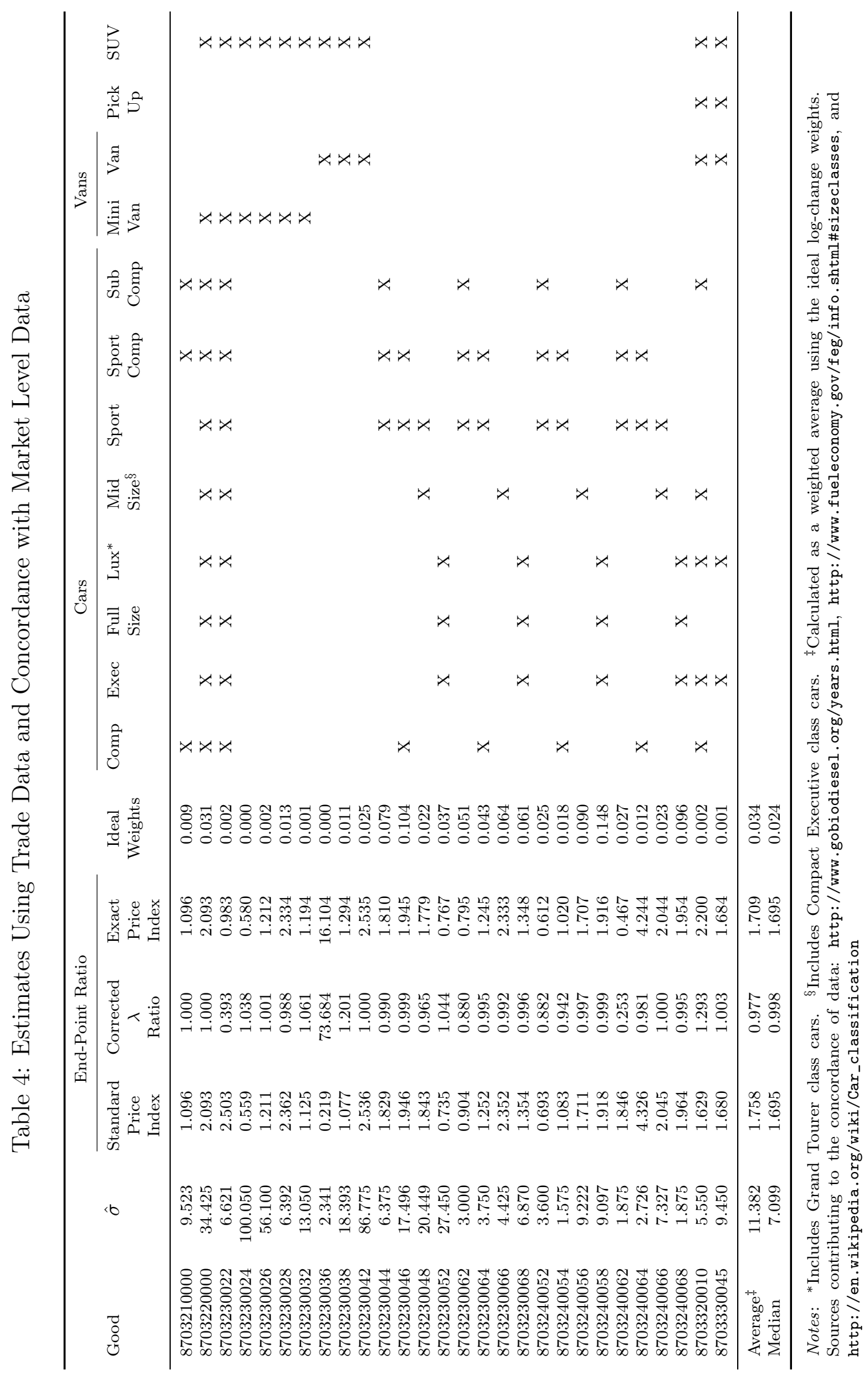


Table 5: Estimates for Imported Market Goods

\begin{tabular}{lrcccc}
\hline & & \multicolumn{3}{c}{ End-Point Ratio } & \\
\cline { 3 - 5 } \multicolumn{1}{c}{ Class } & \multicolumn{1}{c}{$\hat{\sigma}$} & $\begin{array}{c}\text { Standard } \\
\text { Price Index }\end{array}$ & $\begin{array}{c}\text { Corrected } \\
\lambda \text { Ratio }\end{array}$ & $\begin{array}{c}\text { Exact } \\
\text { Price Index }\end{array}$ & $\begin{array}{c}\text { Ideal } \\
\text { Weights }\end{array}$ \\
\hline Compact $^{\dagger}$ & 14.250 & 1.630 & 0.989 & 1.613 & 0.162 \\
Executive & 3.001 & 1.414 & 1.102 & 1.558 & 0.028 \\
Fullsize & 16.650 & 1.505 & 0.941 & 1.416 & 0.059 \\
Luxury & 6.298 & 1.597 & 0.674 & 1.077 & 0.020 \\
Midsize & 18.750 & 1.513 & 0.956 & 1.447 & 0.241 \\
Pickup & 6.535 & 1.854 & 1.015 & 1.881 & 0.151 \\
Sport & 21.629 & 1.651 & 0.954 & 1.575 & 0.029 \\
Sport Compact & 3.305 & 1.300 & 0.985 & 1.281 & 0.003 \\
SUV & 5.341 & 1.762 & 0.780 & 1.355 & 0.242 \\
Van & 9.525 & 1.412 & 0.972 & 1.373 & 0.066 \\
\hline Average & 11.562 & 1.639 & 0.926 & 1.509 & 0.100 \\
Median $^{\ddagger}$ & 8.030 & 1.555 & 0.964 & 0.964 & 0.062 \\
\hline
\end{tabular}

Notes: ${ }^{\ddagger}$ Calculated as a weighted average using the ideal log-change weights. The following classes have been combined with classes possessing highly comparable traits due to the unavailability of a well defined reference variety. ${ }^{\dagger}$ Includes Subcompact. ${ }^{\S}$ Includes in Minivan.

Table 6: Summary Table of Aggregate Endpoint Results across Different Data Sets and Scenarios

\begin{tabular}{|c|c|c|c|}
\hline & $\begin{array}{l}\text { Standard } \\
\text { Price } \\
\text { Index }\end{array}$ & $\begin{array}{c}\text { Corrected } \\
\lambda \\
\text { Ratio }\end{array}$ & $\begin{array}{l}\text { Exact } \\
\text { Price } \\
\text { Index }\end{array}$ \\
\hline \multicolumn{4}{|c|}{$\begin{array}{l}\text { Comparing Estimates Between Import Sample } \\
\text { and Market Sample: }\end{array}$} \\
\hline $\begin{array}{l}\text { Imported Varieites - Import Sample } \\
\text { Imported Varieties - Market Sample }\end{array}$ & $\begin{array}{l}1.657 \\
1.564\end{array}$ & $\begin{array}{l}0.959 \\
0.922\end{array}$ & $\begin{array}{l}1.590 \\
1.442\end{array}$ \\
\hline \multicolumn{4}{|c|}{$\begin{array}{l}\text { Market Sample - Estimates for Imported and } \\
\text { Domestic Varieties: }\end{array}$} \\
\hline $\begin{array}{l}\text { Imported Varieties } \\
\text { Domestic Varieties }\end{array}$ & $\begin{array}{l}1.564 \\
1.666\end{array}$ & $\begin{array}{l}0.922 \\
0.962\end{array}$ & $\begin{array}{l}1.442 \\
1.604\end{array}$ \\
\hline \multicolumn{4}{|c|}{$\begin{array}{l}\text { Market Sample - Estimates for Foreign-owned } \\
\text { and Domestic-owned Varieties: }\end{array}$} \\
\hline $\begin{array}{l}\text { Foreign-owned Varieties } \\
\text { Domestic-owned Varieties }\end{array}$ & $\begin{array}{l}1.564 \\
1.699\end{array}$ & $\begin{array}{l}0.871 \\
0.935\end{array}$ & $\begin{array}{l}1.362 \\
1.589\end{array}$ \\
\hline \multicolumn{4}{|c|}{$\begin{array}{l}\text { Market Sample - Aggregation of Estimates for } \\
\text { Goods by: }\end{array}$} \\
\hline $\begin{array}{l}\text { Production Source } \\
\text { Affiliate Sales }\end{array}$ & $\begin{array}{l}1.628 \\
1.646\end{array}$ & $\begin{array}{l}0.948 \\
0.917\end{array}$ & $\begin{array}{l}1.543 \\
1.509\end{array}$ \\
\hline
\end{tabular}


Table 7: Estimates Using Market Data for Production

\begin{tabular}{|c|c|c|c|c|c|c|c|c|}
\hline \multirow[b]{2}{*}{ Class } & \multicolumn{2}{|c|}{$\hat{\sigma}$} & \multicolumn{2}{|c|}{ Corrected $\lambda$ Ratio } & \multicolumn{2}{|c|}{ Exact Price Index } & \multicolumn{2}{|c|}{ Ideal Log Weights } \\
\hline & Domestic & Foreign & Domestic & Foreign & Domestic & Foreign & Domestic & Foreign \\
\hline Compact & 5.282 & 14.250 & 1.036 & 0.989 & 1.693 & 1.613 & 0.155 & 0.177 \\
\hline Fullsize & 4.200 & 16.500 & 0.924 & 0.964 & 1.407 & 1.420 & 0.100 & 0.153 \\
\hline Midsize & 24.472 & 18.750 & 0.980 & 0.956 & 1.497 & 1.447 & 0.204 & 0.260 \\
\hline Pickup & 8.132 & 6.535 & 0.956 & 1.015 & 1.776 & 1.881 & 0.180 & 0.068 \\
\hline Sport & 13.475 & 9.026 & 1.046 & 0.871 & 1.696 & 1.364 & 0.036 & 0.089 \\
\hline SUV & 17.965 & 5.341 & 0.933 & 0.780 & 1.620 & 1.355 & 0.222 & 0.152 \\
\hline Van & 4.275 & 9.525 & 0.890 & 0.972 & 1.484 & 1.373 & 0.103 & 0.102 \\
\hline
\end{tabular}

Notes: Certain classes have been combined with others possessing highly comparable traits due to the unavailability of a well defined reference variety for both Foreign and Domestically produced goods. Specifically, Compact, Fullsize Midsize, SUV, Sport, and Van include Subcompact, Executive, Crossover SUV, Sport Compact, and Minivan, respectively.

Table 8: Estimates Using Market Data for Affiliates

\begin{tabular}{|c|c|c|c|c|c|c|c|c|}
\hline \multirow[b]{2}{*}{ Class } & \multicolumn{2}{|c|}{$\hat{\sigma}$} & \multicolumn{2}{|c|}{ Corrected $\lambda$ Ratio } & \multicolumn{2}{|c|}{ Exact Price Index } & \multicolumn{2}{|c|}{ Ideal Log Weights } \\
\hline & Domestic & Foreign & Domestic & Foreign & Domestic & Foreign & Domestic & Foreign \\
\hline Compact & 5.629 & 10.065 & 0.890 & 1.032 & 1.437 & 1.680 & 0.114 & 0.272 \\
\hline Fullsize & 20.775 & 12.620 & 0.982 & 0.970 & 1.529 & 1.414 & 0.120 & 0.113 \\
\hline Midsize & 8.081 & 5.550 & 0.956 & 0.781 & 1.539 & 1.137 & 0.193 & 0.275 \\
\hline Pickkup & 7.681 & 13.944 & 0.952 & 0.980 & 1.793 & 1.596 & 0.186 & 0.052 \\
\hline Sport & 9.146 & 12.353 & 1.048 & 0.906 & 1.699 & 1.414 & 0.040 & 0.083 \\
\hline SUV & 6.946 & 11.135 & 0.844 & 0.862 & 1.479 & 1.483 & 0.218 & 0.164 \\
\hline Van & 5.100 & 2.546 & 0.969 & 0.187 & 1.640 & 0.342 & 0.130 & 0.041 \\
\hline
\end{tabular}

Notes: Certain classes have been combined with others possessing highly comparable traits due to the unavailability of a well defined reference variety for both Foreign and Domestically produced goods. Specifically, Compact, Fullsize Midsize, SUV, Sport, and Van include Subcompact, Executive, Crossover SUV, Sport Compact, and Minivan, respectively. 
Table 9: Summary Table of Aggregate Endpoint Results across Different Data Sets and Scenarios

Using Three-year Intervals

\begin{tabular}{|c|c|c|c|}
\hline & $\begin{array}{c}\text { Standard } \\
\text { Price } \\
\text { Index }\end{array}$ & $\begin{array}{c}\text { Corrected } \\
\lambda \\
\text { Ratio }\end{array}$ & $\begin{array}{l}\text { Exact } \\
\text { Price } \\
\text { Index }\end{array}$ \\
\hline \multicolumn{4}{|c|}{$\begin{array}{l}\text { Comparing Estimates Between Import Sample } \\
\text { and Market Sample: }\end{array}$} \\
\hline $\begin{array}{l}\text { Imported Varieites - Import Sample } \\
\text { Imported Varieties - Market Sample }\end{array}$ & $\begin{array}{l}1.749 \\
1.561\end{array}$ & $\begin{array}{l}0.991 \\
0.915\end{array}$ & $\begin{array}{l}1.730 \\
1.428\end{array}$ \\
\hline \multicolumn{4}{|c|}{$\begin{array}{l}\text { Market Sample - Estimates for Imported and } \\
\text { Domestic Varieties: }\end{array}$} \\
\hline $\begin{array}{l}\text { Imported Varieties } \\
\text { Domestic Varieties }\end{array}$ & $\begin{array}{l}1.561 \\
1.687\end{array}$ & $\begin{array}{l}0.915 \\
0.962\end{array}$ & $\begin{array}{l}1.428 \\
1.624\end{array}$ \\
\hline \multicolumn{4}{|c|}{$\begin{array}{l}\text { Market Sample - Estimates for Foreign-owned } \\
\text { and Domestic-owned Varieties: }\end{array}$} \\
\hline $\begin{array}{l}\text { Foreign-owned Varieties } \\
\text { Domestic-owned Varieties }\end{array}$ & $\begin{array}{l}1.546 \\
1.694\end{array}$ & $\begin{array}{l}0.876 \\
0.932\end{array}$ & $\begin{array}{l}1.355 \\
1.579\end{array}$ \\
\hline
\end{tabular}


Figure 1: Comparing Aggregate Estimates for Market and Trade Data
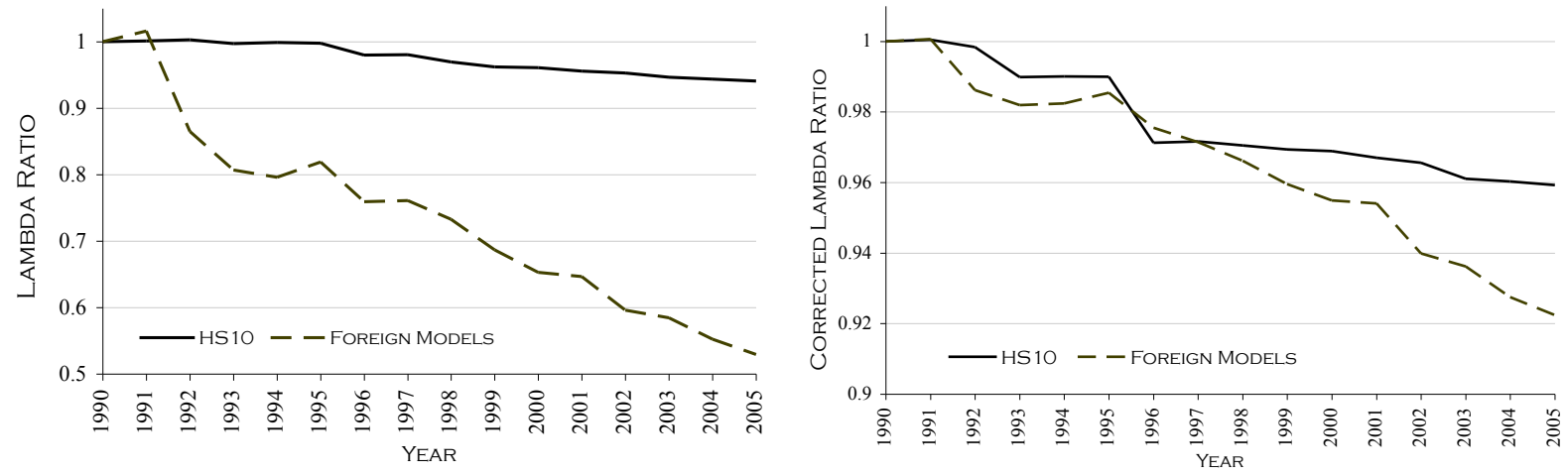

(a) Cumulative Aggregate $\lambda$ Ratio

(b) Cumulative Aggregate Corrected $\lambda$ Ratio
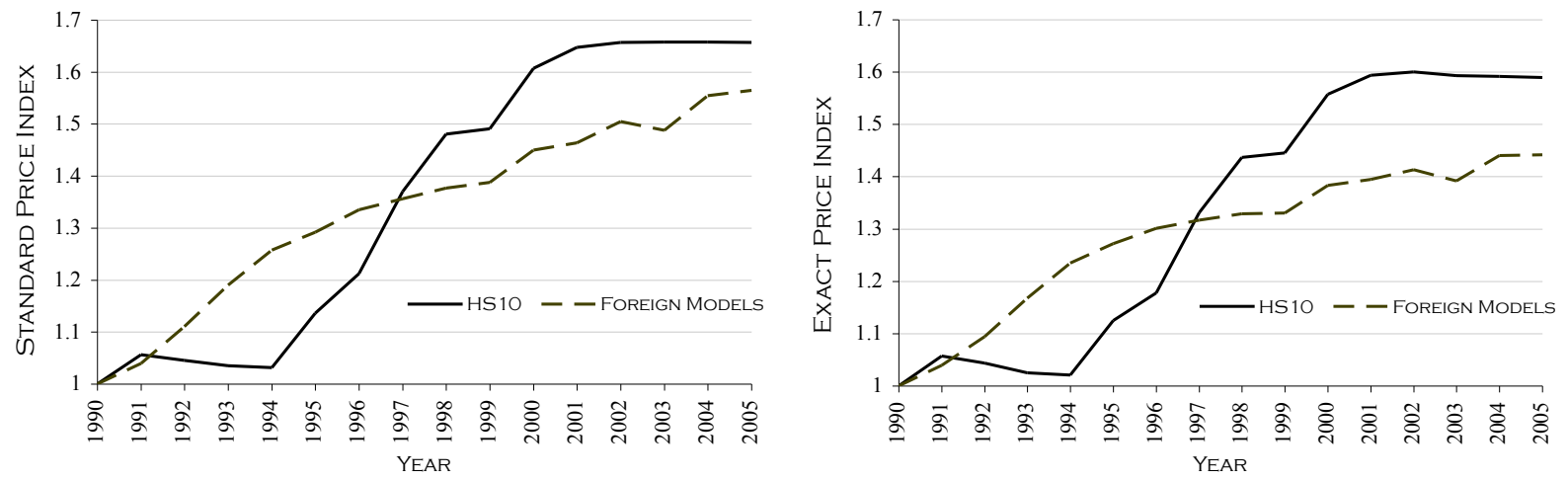

(c) Cumulative Aggregate Standard Price Index

(d) Cumulative Aggregate Exact Price Index 
Figure 2: Comparing Aggregate Estimates for Market and Trade Data in 3 Year Intervals

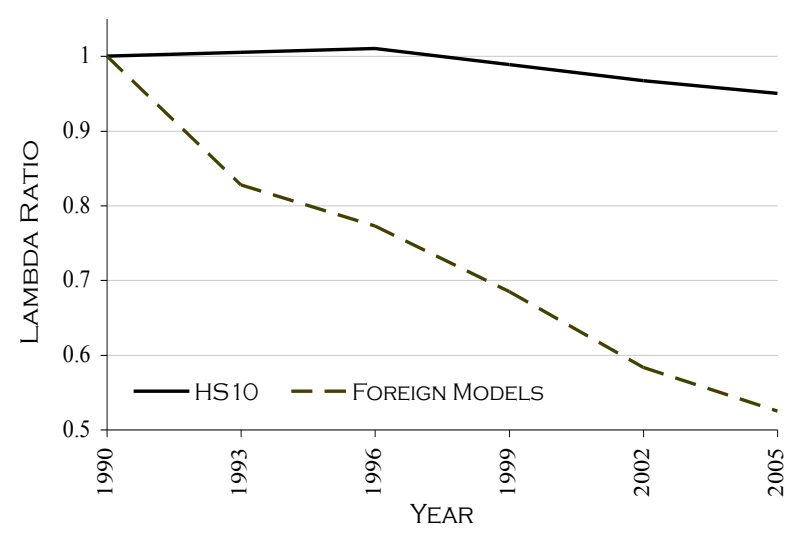

(a) Cumulative Aggregate $\lambda$ Ratio

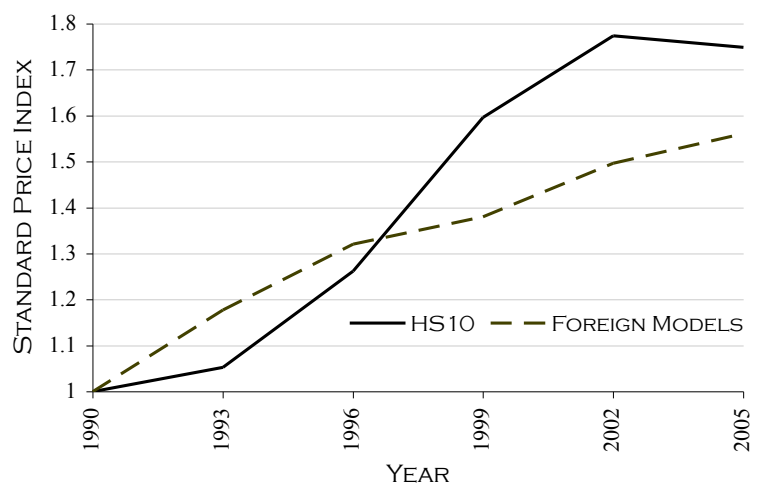

(c) Cumulative Aggregate Standard Price Index

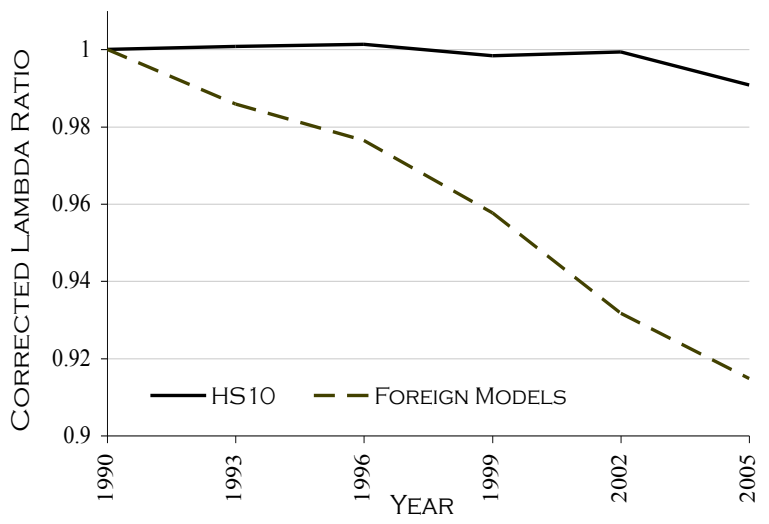

(b) Cumulative Aggregate Corrected $\lambda$ Ratio

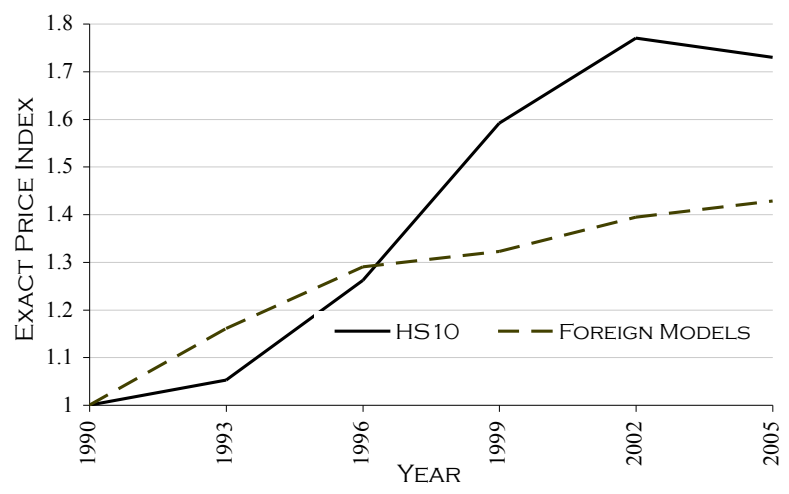

(d) Cumulative Aggregate Exact Price Index 